\title{
Surgical Management of Splenic Echinococcal Disease
}

\author{
G. Meimarakis ${ }^{1}$, G. Grigolia ${ }^{1}$, F. Loehe ${ }^{1}$, K.-W. Jauch ${ }^{1}$, R. J. Schauer ${ }^{1,2}$ \\ ${ }^{1}$ Surgical Department, Klinikum Grosshadern, Ludwig- Maximilians University of Munich, Germany \\ ${ }^{2}$ Surgical Department, Academic Hospital Klinikum Traunstein, Germany
}

\begin{abstract}
Background: Infection of the spleen with echinococcus is a rare clinical entity. Because the diagnosis of a splenic infestation with echinococcus is sometimes delayed, large hydatid cysts or pseudotumors may develop, demanding a differential surgical approach to cure the disease.

Methods: In a retrospective study 10 patients out of 250 with abdominal echinococcosis $(4 \%)$ were identified to have splenic infestation, either limited to the spleen $(n=4)$ or with synchronous involvement of the liver $(\mathrm{n}=4)$, major omentum $(\mathrm{n}=1)$, or the liver and lung $(\mathrm{n}=1)$. Only one patient had alveolar echinococcosis whereas the others showed hydatid cysts of the spleen. Surgical therapy included splenectomy in 7 patients or partial cyst excision combined with omentoplasty in 3 patients. In case of liver involvement, pericystectomy was carried out simultaneously.

Results: There was no mortality. Postoperative complications were observed in 4 patients. Hospital stay and morbidity were not influenced when splenic procedures were combined with pericystectomies of the liver. Mean follow- up was 8.8 years and all of the patients are free of recurrence at this time.

Conclusions: Splenectomy should be the preferred treatment of hydatid cysts but partial cystectomy is suitable when the cysts are located at the margins of the spleen. Due to low morbidity rates, simultaneous treatment of splenic and liver hydatid cysts is recommended.
\end{abstract}

Key words: hydatid disease, spleen, surgical therapy, follow- up

Abbreviations: IEP: immunoelectrophoresis test; IFA: indirect immunofluorescence assay; OLT: orthotopic liver transplantation

\section{INTRODUCTION}

The liver is the most commonly affected organ with echinococcus infection, followed by the lung and the spleen which accounts for 0.5 to $5.8 \%$ of all patients suffering from echinococcal disease $[1,2]$. The rare contamination of the spleen by echinococcus is related to the anatomy of the portal vein system and the deportment of the embryos of the tapeworms by the blood. The adult worms produce eggs that are released into grazing areas with the feces which then can be scattered by environmental influences. After ingestion by the host, i.e. humans, the embryos migrate through the intestinal wall and mature mostly in the liver [3]. Sometimes, the eggs may penetrate the circulation without forming cysts in the liver, thus enabling them to settle in other organs via the blood flow. However, it is also possible that when a human host has a fissured cyst, scolices or daughter hydatids can migrate through the wall of the cyst. They can be released to the body and may form new cysts in nearby or distant organs, such as the spleen (secondary echinococcosis) [3, 4]. Literature which focuses on splenic echinococcosis is, so far based on sporadic cases, and seems inconsistent with regard to splenectomy, spleen- preserving surgery or interventional treatment options as the recommended procedure in that cases $[5,6,7]$.

This report concerns 10 patients who underwent surgery for splenic echinococcal disease in our hospital. We analyzed clinical signs, diagnostic and surgical proceduers as well as the long-term outcome of the patients.

\section{Patients AND Methods}

Between 1982 and 2004 a total of 250 patients with abdominal echinococcus disease underwent surgery at our institution. During this period, 10 patients underwent operation because of an involvement of the spleen with echinococcus. These patients were retrospectively identified by analysis of patients records. In consequence, splenic echinococcosis represented $4 \%$ of abdominal echinococcus disease treated in our center. The spleen was the sole site of infection in 4 cases whereas the other patients had synchronous diesease of the liver (4 cases), the peritoneum (1 case) or combined infection of the liver and the lung (Table 1). The mean age of the patients was 37.7 years $(22-57$ ys.) and females had a greater risk to acquire the disease $(8: 2)$. There was only one patient (No. 9) who developed infection of the spleen with E. multilocularis. This patient underwent orthotopic liver transplantation (OLT) due to alveolar echinococcosis one year before. Therefore, splenic involvement in this case was considered as recurrence of the original disease rather than a de novo infection.

Diagnosis was based on imaging techniques, including ultrasound examination and computed tomography (CT) as well as immunologic tests, such as the immunoelectrophoresis test (IEP) and the indirect im- 
Table 1. Patients characteristic when admitted to our institution.

\begin{tabular}{|c|c|c|c|c|c|}
\hline Pat.- No. & Age/sex & $\begin{array}{c}\text { Form of } \\
\text { echinococcosis }\end{array}$ & $\begin{array}{l}\text { Size of the } \\
\text { splenic cyst }\end{array}$ & $\begin{array}{l}\text { Additional cysts / } \\
\text { size of infestation }\end{array}$ & $\begin{array}{c}\text { History of hydatid } \\
\text { diesease }\end{array}$ \\
\hline 1 & $32 / \mathrm{F}$ & E. granulosus & $8 \mathrm{~cm}$ & $\mathfrak{x}$ & No \\
\hline 2 & $28 / \mathrm{F}$ & E. granulosus & $10 \mathrm{~cm}$ & $æ$ & No \\
\hline 3 & $41 / \mathrm{F}$ & E. granulosus & $7 \mathrm{~cm}$ & $\mathfrak{x}$ & No \\
\hline 4 & $47 / \mathrm{F}$ & E. granulosus & $12 \mathrm{~cm}$ & $\mathfrak{x}$ & No \\
\hline 5 & $57 / \mathrm{F}$ & E. granulosus & $6 \mathrm{~cm}$ & Liver $/ 6.5 \mathrm{~cm}$ & No \\
\hline 6 & $31 / \mathrm{M}$ & E. granulosus & $8 \mathrm{~cm}$ & Liver $/ 5.0 \mathrm{~cm}$ & No \\
\hline 7 & $30 / \mathrm{F}$ & E. granulosus & $9 \mathrm{~cm}$ & Liver $/ 8.0 \mathrm{~cm}$ & No \\
\hline 8 & $43 / \mathrm{M}$ & E. granulosus & $6 \mathrm{~cm}$ & Liver $(8.0 \mathrm{~cm})$ & No \\
\hline 9 & $22 / \mathrm{F}$ & E. multilocularis & $2.5 \mathrm{~cm}$ & Major omentum $/ 2.0 \mathrm{~cm}$ & Yes, OLT \\
\hline 10 & $46 / \mathrm{F}$ & E. granulosus & $12 \mathrm{~cm}$ & $\begin{array}{l}\text { Lung } / 7.5 \mathrm{~cm} \\
\text { Liver } / 9.0 \mathrm{~cm}\end{array}$ & No \\
\hline
\end{tabular}

Table 2. Clinical symptoms and diagnostic procedures.

\begin{tabular}{lcccc}
\hline Pat. No. & Eosinophilia & Immunologic testing & Imaging studies & Symptomes \\
\hline 1 & $\mathfrak{1}$ & + & US, CT & Mild abd. pain \\
2 & + & + & US & Mild abd. pain \\
3 & $x$ & + & US & Abd. discomfort, nausea \\
4 & $æ$ & $x$ & US, CT & Mild abd. pain \\
5 & $x$ & + & US, CT & Mild abd. pain \\
6 & $x$ & US, CT & Mild abd. pain \\
7 & $x$ & US, CT & Mild discomfort right upper abd. \\
8 & + & + & US, CT & Severe abd. pain \\
9 & + & + & US & none \\
10 & + & + & US, CT, ThXr & Palpable mass, dypnoe \\
\hline
\end{tabular}

Note: US, ultrasound; CT, computed tomography; ThXr, X-ray of the thorax. Eosinophilia and immunological testing were determined after detection of cystic disease. Immunologic testing consisted of immunoelectrophoresis test (IEP) or by indirect immunofluorescence assay (IFA).

munofluorescence assay (IFA) [8, 9]. Additionally, medical history and the clinical symptoms of the patients were guidelines for establishing the diagnosis (Table 2).

In all patients surgery was performed as an open procedure and all patients received prophylactic vaccination (Pneumovax ${ }^{\circledR}$ ) to avoid infections. When the spleen was the only site of echinococcal disease, we approached the abdominal cavity via a left subcostal incision. When the liver was simultaneously involved, we performed a transverse laparotomy, enabling cure of both organs from the disease at the same time. Only the patient with hydatidosis of the lung, the liver and the spleen was operated in two stages, beginning with the resection of the inferior lobe of the right lung. After complete recovery of this patient, a combined approach with splenectomy and pericystectomy of the liver was carried out. All surgical procedures were performed under medical prophylaxis either with mebendazole or albendazole, respectively [10]. This therapy was postoperatively continued in all patients for at least six month or until immunologic tests became negative (Table 3). The basic principles of the surgical procedure were an entire elimination of the parasite, no intraoperative spillage, and saving of healthy tissue. Therefore, we used partial cystectomy in combination with an omentoplasty whenever possible in the spleen and, consequently, the pericystectomy procedure when the liver was involved $[11,12]$. Because this practice principally contained the risk of contamination with infective material, we stuffed the abdominal cavity with high-concentrated (25\%) salinesoaked towels immediately next to the cysts which is a common recommendation in the literature [13]. Prior to resection, the cyst was evacuated by a sump- drain and the cavity was then filled with saline solution $(25 \%)$. At the end of the operation the cavity was filled with omentum which was additionally fixed by sutures at the edges of the remnant cyst wall. In contrast, splenectomy does not require specific precautions with solicidal agents, in particular when the cysts are located amidst normal parenchyma. 
Table 3. Surgical treatment and outcome of patients.

\begin{tabular}{|c|c|c|c|c|c|c|}
\hline Pat.- No. & Surgery & $\begin{array}{l}\text { Complications/ } \\
\text { therapy }\end{array}$ & $\begin{array}{l}\text { Hospital } \\
\text { stay }(\mathrm{d})\end{array}$ & $\begin{array}{l}\text { Medical } \\
\text { prophylaxis }\end{array}$ & $\begin{array}{l}\text { Current } \\
\text { status }\end{array}$ & $\begin{array}{c}\text { Follow up } \\
\text { (years) }\end{array}$ \\
\hline 1 & Splenectomy & DVT/ anticoagulation & 14 & Mebendazole & FOR & 10.1 \\
\hline 2 & Splenectomy & $æ$ & 9 & Mebendazole & FOR & 16.6 \\
\hline 3 & $\begin{array}{l}\text { Partial cystectomy, } \\
\text { omentoplasty }\end{array}$ & $æ$ & 11 & Albendazole & FOR & 12.6 \\
\hline 4 & $\begin{array}{l}\text { Partial cystectomy, } \\
\text { omentoplasty }\end{array}$ & $æ$ & 9 & Albendazole & FOR & 11.6 \\
\hline 5 & $\begin{array}{l}\text { Splenectomy, } \\
\text { pericystectomy (liver) }\end{array}$ & $æ$ & 6 & Mebendazole & FOR & 7.6 \\
\hline 6 & $\begin{array}{l}\text { Splenectomy } \\
\text { pericystectomy (liver) }\end{array}$ & $\mathfrak{x}$ & 7 & Mebendazole & FOR & 4.7 \\
\hline 7 & $\begin{array}{l}\text { Splenectomy } \\
\text { pericystectomy (liver) }\end{array}$ & $æ$ & 8 & Albendazole & FOR & 2.7 \\
\hline 8 & $\begin{array}{l}\text { Partial cystectomy, } \\
\text { omentoplasty } \\
\text { pericystectomy (liver) }\end{array}$ & $\begin{array}{c}\text { Pleural effusion/ } \\
\text { drainage }\end{array}$ & 7 & Albendazole & FOR & 8.4 \\
\hline 9 & $\begin{array}{l}\text { Splenectomy, resection } \\
\text { of major omentum }\end{array}$ & $\begin{array}{l}\text { Wound infection/ } \\
\text { conservative }\end{array}$ & 8 & Mebendazole & FOR & 14.6 \\
\hline 10 & $\begin{array}{l}\text { Splenectomy } \\
\text { pericystectomy (liver) } \\
\text { Resection of inferior } \\
\text { lobe (right lung) }\end{array}$ & $\begin{array}{l}\text { Abscess in the } \\
\text { liver/ } \\
\text { puncture and } \\
\text { drainage }\end{array}$ & 6 & Albendazole & FOR & 6.7 \\
\hline
\end{tabular}

Note: DVT, deep vein thrombosis; FOR, free of recurrence. Details of operative procedures, see text.

The house doctors as well as the patients were interviewed in order to gain follow- up data. In all cases, the obtained information was satisfactory to decide whether a patient was free of recurrent disease. This assumption was confirmed by up-to-date immunologic tests and abdominal imaging (ultrasound examination), respectively. Mean follow- up time was 8.8 years (2.716.6 years).

\section{RESULTS}

Most of our patients presented no overt clinical symptoms. The main complaint was mild abdominal pain, mostly located in the left upper quadrant. One patient (No. 7) had non- characteristic symptoms in the upper right abdomen which may be attributed to the liver hydatid cyst of $8 \mathrm{~cm}$ in diameter. Another patient (No. 10) presented with a palpable mass in the left hypochondrium and with marked dyspnoe (Tables 1, 2). In this patient, chest radiographs showed multiple calcifications in hydatids of the lung as well as of the spleen.

In only 2 cases the preoperative ultrasound examination was highly sensitive for the diagnosis of a hydatid cyst due to characteristic features, such as membranes within the cyst and some calcifications (Table 2). In all other patients further imaging studies were necessary for the diagnosis of echinococcal disease. However, even CT- scans did not always allow the correct diagnosis as indicated by the lack of typical signs within the cyst in 5 out of 9 patients with hydatid disease $(55 \%)$.

Therefore, serological tests were initiated when ultrasonography or CT scans revealed cystic lesions in the spleen or liver and an infection with echinococcus was assumed. However, as indicated in Table 2 eosinophilia was very uncommon in our patients, whereas specific immunological tests failed to establish the diagnosis only in one case.

In all patients the diagnosis of echinococcal disease was confirmed during operation or at histological work- up. A single cyst of the spleen was observed in all cases, even in the patient with E. multilocularis infection (No. 9) the 'tumor' represented as a cystic lesion. The spleen was removed in 7 cases; only in 3 patients a spleen- sparing surgical treatment was achieved (Table 3). In these patients (No. 3, 4, 8) the hydatid cyst was located at the upper or lower pole of the spleen with its major portion outside the splenic parenchyma. Therefore, it seemed possible to preserve the spleen by partial resection of the cyst. In 6 patients additional surgical procedures were necessary because of involvement of other organs. The infiltration of the major omentum with echinococcus multilocularis (patient No. 9) was an incidental finding during operation and required complete resection. The mean diameter of hydatid cysts of the liver was $7.3 \mathrm{~cm}(5-9 \mathrm{~cm}$, Table 1). All of these cysts were located in the right liver lobe (segment VI, $\mathrm{n}=2$ and segment VII, $\mathrm{n}=3$ ). In all these cases, a pericystectomy of the liver was performed prior to the splenectomy (Table 3).

All patients recovered shortly after surgery (Table $3)$. There was no mortality in these patients. We observed 3 operation- related complications, including one deep vein thrombosis, one wound infection and one liver abscess, the latter of these requiring intervention by puncture and drainage. The duration of 
hospitalization ranged from 6 to 14 days (mean 8.5 days). All of the patients were discharged home, but underwent control examination as out- patients one week later. Interestingly, we observed a shorter hospital stay when a combined operation, i.e splenectomy plus pericystectomy was necessary.

Follow- up ranged from 2.7 years to 16.6 years (mean 8.8 years). During this period none of the patients required further operation. The perioperative prophylaxis with mebendazole or albendazole was continued postoperatively in all patients for another six months. At the time of follow- up examinations, all patients were free of disease as indicated by various imaging studies as well as by negative immunologic tests.

\section{DISCUSSION}

Echinococcal infection is caused by the larval form of the cestode Echinococcus, with E. granulosus accounting for about $95 \%$ of all cases of hydatid disease [14]. In humans, the larval metacestode stage causes cystic hydatid disease which is characterized by the expansive growth of larval cysts, mostly in the liver and less frequently in other organs $[1,2]$. Infection in man by the larval stage of E. multilocularis causes alveolar hydatid disease which is characterized by the proliferation of a multivesicular, larval tissue with a tumor- like infiltration of host tissues [15]. In Central Europe, alveolar hydatid disease represents by far the most serious form of Echinococcus infection in man. Recently, the annual mean incidence of newly diagnosed cases of echinococcal disease in endemic regions of Germany was calculated to be 0.04 per 100.000 [16]. However, this rate is markedly different from the incidences of highly endemic areas, such as Israel (7.0$45.9 / 100.000 /$ year $)$ or Tunesia (15.1/100.000/year) [17].

The clinical course of echinococcal infection is highly variable and depends on the localization, extent and proliferation of the larval tissue as well as on the host reaction. In our institution and in most reports in the literature splenic hydatidosis occupies the third place behind hepatic and pulmonary hydatid disease. Its frequency varies between 0.5 and $8 \%(1-3)$; in our series it was calculated as $4 \%$. Additional hepatic or pulmonary involvement occurs in $20-30 \%$ of cases [6] which is a lower rate than we observed in our patients $(55 \%)$. This discrepancy may be explained by the relatively late diagnosis of echinococcal disease due to the mild symptoms of the majority of patients. Furthermore, the presence of a hydatid cyst in the liver with a mean size in this series of $7.3 \mathrm{~cm}$ might be the cause for secondary echinococcosis of the spleen $[3,18]$.

In our patients a single large hydatid cyst, comprising a substantial part of the splenic parenchyma existed in all, but one case. In patient No.9 only a $2.5 \mathrm{~cm}$ cystic lesion was recognized in the US scan during routine follow- up after liver transplantation. Because this patient did not develop any symptoms in the left hypochondrium, one has to be aware that only large hydatid cysts may cause patient complaints which can force diagnostic procedures. However, clinical manifestations of splenic hydatid disease are usually mild and nonspecific, even when the cysts reach a consider- able size. Five patients presented with mild abdominal pain as the only symptom. Another patient developed mild discomfort only in the right hypochondrium which was due to the cyst in the liver whereas the cyst in the spleen $(9 \mathrm{~cm}$ in diameter) was clinically inapperant. A hard, round mass could be palpated in the left hypochondriac region in patient No.10, however, the diagnosis was made by standard chest radiography which was initiated because of prolonged dyspnoe. These images revealed a cystic disease in the right lung, the liver, and the spleen. Because partial calcification of the cysts were considered as typical features [19], the diagnosis of echinococcal disease was established. Complications, such as secondary infection, cyst rupture into the abdominal cavity, and anaphylactic shock have been reported, but seem mainly related to very large splenic cysts $[20,21]$.

Today, the diagnosis of splenic hydatidosis is greatly aided by ultrasonography (US) and, in particular CT scans $[22,23]$. However, sonographic and CT findings of splenic cysts are not specific because other cystic lesions may present with similar appearances on US and CT $[5,24]$. Due to the diagnostic uncertainty, Gharbi and coworkers introduced 5 types of US morphology of hydatid cysts which should help to find the right diagnosis [25]. The US findings of patients No.4 and 10 illustrates the difficulties which may be encountered during diagnostic work- up; the hydatid cysts appeared as a pure cystic lesion (Gharbi type 1) without membranes, daughter cysts or calcifications, thus hardly to be identified as a parasitic cyst. However, synchronous cystic lesions in the liver may guide to the diagnosis of echinococcal disease of the spleen. Several immunologic tests may also help in the diagnosis, although laboratory data are sometimes uncertain; hepatic hydatidosis is reported to be confirmed in 80$94 \%$, but extrahepatic hydatidosis only in $65 \%$ of cases, even when the immunologic tests are based on multiple methods $[8,9]$. In our series, the immunological testing consisted of immunoelectrophoresis test (IEP) or the indirect immunofluorescence assay (IFA). IEP- test normally allows the diagnosis of hepatic hydatidosis in $94 \%$ [26], but has only a low sensitivity when an extrahepatic manifestation of echinococcal disease is present. In contrast, the serologic response of the IFA test is highest in the presence of hepatic or splenic hydatidosis [27]. Only one patient (No.4) of our series was not recognized by laboratory testing (IEP), but all patients who presented with additional hydatid cysts outside of the spleen were positive in the immunological tests, confirming some reports in the literature [8]. In contrast, the determination of eosinophilia in patients with cystic disease seems to be of little help [8].

Surgery is the mainstay of treatment for hydatid disease of the spleen and several surgical techniques have been applied to splenic echinococcosis, including spleen- sparing operations $[5,7,28]$. As for these cases, the splenic cyst is evacuated by a sump drain after unroofing of the cyst wall and the residual cavity is then filled with a $25 \%$ saline solution, followed by an omentoplasty. Different scolicidal agents have been proposed to prevent spillage of infectious material during resection of the cysts. However, some of these 
substances showed only in vitro activity and thus were not superior to hypertonic saline, as used in this series [29]. Additionally, the omentoplasty fills the cavity by a pediculated part of the greater omentum, a procedure which proofed to reduce postoperative complications, including biliary fistulas [30]. An organ- sparing approach seems favourable when the cysts are located at the splenic surface or at the poles of the spleen as in 3 of our patients $($ No.3, 4,8). In contrast to the unroofing and evacuation of hydatid cysts of the spleen, splenic salvage by cyst enucleation or partial splenectomy may often be related to a considerable blood loss. Furthermore, due to the difficulty of vascular control during parenchymal transection, these operations preclude a laparoscopic approach as it is feasible for splenectomies or for deroofing of the cyst wall [31].

Although the preservation of the spleen is being increasingly advocated to prevent some complications associated with splenectomy [32], only the complete removal of the diseased organ rids the patient of a potentially infected cavity which carries the risk of recurrence [33]. For this reason as well as an unrecognized infection with E. multilocularis, we are in favor of splenectomy. As we could demonstrate, this procedure can be associated with no mortality and a low morbidity which is similar to that observed after surgery for hepatic hydatidosis [1, 19]. Moreover, one of the postoperative complications was related to a pericystectomy of the liver (patient No.10) and another complication might be the result of a re- laparotomy in an immunosuppressed patient (No.9) rather than the consequence of a splenectomy.

In the case of additional hepatic disease, splenectomy is followed by surgical management of hepatic cysts, usually pericystectomy as in our patients. The combined therapy of the liver and the spleen during one single operation seems feasible $[9,34]$ which is in line with our observation that there was no enhanced morbidity in these patients. After splenectomy the patients are more susceptible to infections or even sepsis, in particular in childhood $[32,35]$. Therefore, all patients underwent prophylactic vaccination prior to surgery to significantly reduce that specific risk $[35,36]$.

Recently, percutaneous aspiration, combined with the injection of scolicidal agents into the cyst cavity under radiologic guidance has been introduced as an alternative to surgical treatment of hydatid cysts of the liver, indicating lower complication rates and a shorter hospital stay than open surgery [37]. However, cyst puncture may lead to spillage of infectious material with the risk of dissemination of a primarly limited disease $[37,38]$ and, moreover, there is no data to do this procedure in splenic cysts [38].

Hydatid cysts are known to recur with a frequency from 8 to $20 \%$ following a hepatic infestation [33]. Although reliable data are missing, recurrance rates after splenic hydatidosis seem very low following splenectomy, but might be higher after spleen- sparing operations or when additional cysts were removed from other organs. Therefore, medical prophylaxis should be given to patients perioperatively as well as during the first 6 month after surgery, usually including albendazole or mebendazole [39].
In conclusion, splenectomy remains the therapeutic procedure of choice because it offers the complete cure from the disease with low mortality- and morbidity rates. We could also demonstrate that splenectomy or partial cystectomy of the spleen can safely be combined with procedures related to hydatid disease of the liver. Spleen- preserving surgery should be indicated carefully whereas in the future, interventional procedures might gain increasing significance as a therapeutic option.

\section{REFERENCES}

1. Magistrelli P, Masetti R, Coppola R, Messia A, Nuzzo G, Picciochi A. Surgical treatment of hydatid disease of the liver. World J Surg 1991;126:518-523

2. Prousalidid J, Tzardinoglou K, Sgouradis L, Katsohis C, Aletras H. Uncommon sites of hydatid disease. World J Surg 1998;22:17-22

3. Bourée P. Hydatidosis: dynamics of transmission. World J Surg 2001;25:4-9

4. Eckert J, Deplazes P. Biological, epidemiological, and clinical aspects of echinococcosis, a zoonosis of increasing concern. Clin Microbiol Rev 2004;17:107-135

5. Alkofer B, Lepennec V, Chiche L. Splenic cysts and tumors: diagnosis and management. J Chir (Paris) 2005; 142:6-13

6. Reuter S, Seitz HM, Kern P, Junghanss T. Extrahepatic alveolar echinococcosis without liver involvement: a rare manifestation. Infection 2000;28:187-192

7. Manouras AJ, Nikolaou CC, Katergiannakis VA, Aposolidis NS, Golematis BC. Spleen- sparing treatment for echinococcosis of the spleen. Br J Surg 1997;84:1162

8. Biava MF, Dao A, Fortier B. Laboratory diagnosis of cystic hydatid disease. World J Surg 2001;25:10-14

9. Carmena D, Benito A, Eraso E. The immunodiagnosis of echinococcus multilocularis infection. Clin Microbiol Infect 2007;13:460-475

10. Davidson RN, Brycecon AD, Cowie AG, McManus DP. Pre-operative albendazole therapy and hydatid cysts. Br J Surg 1988;75:398

11. Cirenei A, Bertoldi I. Evolution of surgery for liver hydatidosis from 1950 to today: analysis of a personal experience. World J Surg 2001;25:87-92

12. Moreno Gonzales E, Rico Selas P, Martinez B, Garcia Garcia I, Palma Carazo F, Hidalgo Pascual M. Results of surgical treatment of hepatic hydatidosis: current therapeutic modifications. World J Surg 1991;15:254-263

13. Buttenschoen K, Buttenschoen DC. Echinococcus granulosus infection: the challenge of surgical treatment. Langenbecks Arch Surg 2003;388:218-230

14. Pawlowski ZS, Eckert J, Vuitton D, Ammann RW, Kern P, Craig PS, Dar FK, De Rosa F, Filice C, Gottstein B, Grimm F, Macpherson CNL, Sato N, Todorov T, Uchino J, v. Sinner W, Wen H. Echinococcus in humans: clinical aspects, diagnosis and treatment. In: Eckert J, Gemmell MA, Meslin FX, Pawlowski Z (eds). WHO/OIE manual on echinococcosis in humans and animals: a public health problem of global concern (Paris, 2001), pp 20-71

15. Czermak BV, Unsinn KM, Gotwald T, Waldenberger P, Freund MC, Bale RJ, Vogel W, Jaschke WR. Echinococcus multilocularis revisited. AJR 2001;176:1207-1212

16. Nothdurft HD, Jelinek T, Mai A, Sigl B, von Sonnenburg $\mathrm{F}$, Loescher T. Epidemiology of alveolar echinococcus in Southern Germany (Bavaria). Infection 1995;23:85-88

17. WHO/OIE manual on echinococcosis in humans and animals: a public health problem of global concern. World Organisation for animal health and World Health Organisation, Paris, France (2001) 
18. McManus DP, Zhang W, Li J, Bartley PB. Echinococcosis. Lancet 2003;362:1295-1304

19. Sayek I, Onat D. Diagnosis and treatment of uncomplicated hydatid cyst of the liver. World J Surg 2001;25:2127

20. Caballero P, Ocon E, Robledo AG, Diaz FJ. Splenic hydatid cyst opening to the colon. AJR 1986;147:859

21. Lygidakis NJ. Diagnosis and treatment of intrabiliary rupture of hydatid cyst of the liver. Arch Surg 1983;118: 1186-1189

22. Caremani M, Benci A, Maestrini R, Accorsi A, Caremani $\mathrm{D}$, Lapini L. Ultrasound imaging in cystic echinococcosis. Proposal of a new sonographic classification. Acta Trop 1997;67:91-105

23. Gossios KJ, Kontoyiannis DS, Dascalogiannaki M, Gourtsoyiannis NC. Uncommon locations of hydatid disease: CT appearances. Eur Radiol 1997;7:1303-1308

24. Dachmann AH, Ros PR, Murari PJ, Olmstead WW, Lichtenstein JE. Nonparasitic splenic cysts: a report of 52 cases with radiologic-pathologic correlation. AJR 1986; 147: 537

25. Gharbi HA, Hassine W, Brauner MW, Dupuch K. Ultrasound examination of hydatic liver. Radiology 1981;139: 549

26. Capron A, Yarzabal L, Vernes A, Fruit J. Le diagnostic immunologique de l'échinococcose humaine (bilance personnel à partir de 400 observations). Pathol Biol 1970; 18:357

27. Coudert J, Ambroise-Thomas P, Kein-Truong A. Le diagnostic sérologique du kyste hydatique par immuno- fluorescence sur coupes de scolex. Cab Med Lyon 1967;45:27

28. Bhatnagar V, Agarwala S, Mitra DK. Conservative surgery for splenic hydatid cyst. J Pediatr Surg 1994; 29: 1570-1571

29. Adas G, Arikan S, Kemik O, Oner A, Sahip N, Karatepe O. Use of albendazole sulfoxide, albendazole sulfone, and combined solutions as solicidal agents on hydatid cysts (in vitro study). World J Gastroenterol 2009;15:112-116

30. Ozacmak ID, Ekiz F, Ozmen V, Isik A. Management of residual cavity after partial cystectomy for hepatic hydatidosis: comparison of omentoplasty with external drainage. Eur J Surg 2000;166:696-699
31. Khoury G, Abiad F, Geagea T, Nabout G, Jabbour S. Laparoscopic treatment of hydatid cysts of the liver and spleen. Surg Endosc 2000;14:243-245

32. Brigden ML, Pattullo AL. Prevention and management of overwhelming postsplenectomy infection - an update. Crit Care Med 1999;27:836-842

33. Little JM, Hollands MJ, Ekberg H. Recurrence of hydatid disease of the liver. World J Surg 1988;12:700-704

34. Milicevic M. Hydatid disease. In: Blumgart LH, Fong Y (eds). Surgery of the liver and biliary tract. Saunders, Philadelphia 2000; pp 1167-1204

35. Jugenburg M, Haddok G, Freedman MH, Ford-Jones L, Ein SH. The morbidity and mortality of pediatric splenectomy: does prophylaxis make a difference? J Pediatr Surg 1999;34:1064-1067

36. Ejstrud P, Kristensen B, Hansen JB, Madsen KM, Schonheyder HC, Sorensen HAT. Risk and patterns of bacteriaemia after splenectomy: a population- based study. Scand J Infect Dis 2000;32:521-525

37. Örmeci N, Soykan I, Bektas A, Sanoglu M, Palabiyikoglu M, Hada-Yasa M, Dökmeci A, Uzunalimoglu Ö. A new percutaneous approach for the treatment of hydatid cysts of the liver. Am J Gastroenterol 2001;96:2225-2230

38. Akcan A, Akyildiz H, Artis T, Ozturk A, Deneme MA, Ok E, Sozuer E. Peritoneal perforation of liver hydatid cysts: clinical presentation, predisposing factors, and surgical outcome. World J Surg 2007;31:1284-1291

39. Saimot AG. Medical treatment of liver hydatidosis. World J Surg 2001;25:15-20

Received: February 9, 2009 / Accepted: March 2, 2009

Address for correspondence:

Rolf J. Schauer, M.D.

Surgical Department

Klinikum Traunstein

Cuno-Niggl-Str. 3

83278 Traunstein

Germany

Fax: $\quad+49(0) 861 / 705-1470$

Phone: +49(0)861/705-1201

E-mail_rolf.schauer@klinikum-traunstein.de 